\title{
Exercise and eating behaviour: the role of mindfulness
}

\author{
Rachel Martin ${ }^{1}$, Ivanka Prichard ${ }^{2 *}$, Amanda D. Hutchinson², Carlene Wilson ${ }^{2}$ \\ From 2013 ANZAED Conference: Inspiring Change: Person and Context \\ Melbourne, Australia. 23-24 August 2013
}

The present study examined yoga participation and cardiovascular exercise in relation to dietary intake and disordered eating symptomatology and the role of mindfulness. Participants were 159 female exercisers who completed a questionnaire incorporating measures of exercise behaviour, body awareness, trait mindfulness, mindful eating, and dietary intake and disordered eating symptomatology. Participation in yoga was associated with significantly lower levels of disordered eating symptomatology whereas the amount of time spent participating in cardio-based exercise was associated with greater eating disturbance. The relationship between yoga participation and eating behaviour was mediated by both trait mindfulness and body awareness; the relationship between cardio-based exercise and eating behaviour was partially mediated by trait mindfulness. The relationships between amount of exercise and actual food intake were not mediated by trait mindfulness or body awareness. The differential findings for dietary intake and disordered eating proneness indicate that mindfulness may be more beneficial for clinical populations or those at risk for eating disorders than for modifying actual dietary intake in the general population.

This abstract was presented in the Disordered Eating Characteristics \& Treatment stream of the 2013 ANZAED Conference.

\section{Authors' details}

'School of Psychology, Flinders University, Australia. ${ }^{2}$ Flinders Centre for Innovation in Cancer, School of Medicine, Australia.

Published: 14 November 2013

* Correspondence: ivanka.prichard@flinders.edu.au

${ }^{2}$ Flinders Centre for Innovation in Cancer, School of Medicine, Australia

Full list of author information is available at the end of the article
doi:10.1186/2050-2974-1-S1-024

Cite this article as: Martin et al:: Exercise and eating behaviour: the role of mindfulness. Journal of Eating Disorders 2013 1(Suppl 1):O24.
Submit your next manuscript to BioMed Central and take full advantage of:

- Convenient online submission

- Thorough peer review

- No space constraints or color figure charges

- Immediate publication on acceptance

- Inclusion in PubMed, CAS, Scopus and Google Scholar

- Research which is freely available for redistribution
C Biomed Central
C Biomed Central

C 2013 Martin et al; licensee BioMed Central Lt

Atribution Lict dis an any medium, provided the original work is properlicenses/by/2. 